\title{
Effects of Environmental Factors on the Growth, Optical Density and Biomass of the Green Algae Chlorella Vulgaris in Outdoor Conditions
}

\section{LAVAJOO FATEMEH ${ }^{1}$; DEHGHANI MOHSEN ${ }^{1}$}

\author{
${ }^{I}$ Department of marine biology, Faculty of Sciences, University of Hormozgan, Bandar abbas, Iran. P.O.Box 3995. \\ (Corresponding author: f.lavajoo@gmail.com)
}

\begin{abstract}
Effect of environmental factors on the growth of the Chlorella vulgaris was studied. C. vulgaris was cultivated in sterilized natural seawater enriched with $\mathrm{F} / 2-\mathrm{Si}$ medium. Then grow in bucket, tub and photobioreactor (PBR) in outdoor condition. The daily routine work consisted of culture checkups of optical density, biomass gains, atmosphere lux, culture lux, atmosphere temperature and culture temperature were recorded. The highest biomass yields were $\left(3.0 \mu \mathrm{g} / \mathrm{ml}^{-1}\right)$ in December and $\left(2.01 \mu \mathrm{g} / \mathrm{ml}^{-1}\right)$ in November in PBR. The highest deviation was in atmosphere lux in time 8:30 $( \pm 117.7)$ and lowest deviation was in atmosphere temperature in time 15:00 ( \pm 1.0499$)$. Optical density (OD) indicated that the best growth of $C$. vulgaris in outdoor condition was obtained in 650 lux and also it increased with increasing amount of lux. Tub report of $C$. vulgaris showed different growing behaviors at the various concentration of light and at the different temperatures. Algal production in outdoor PBR is relatively inexpensive, but is only suitable for a few, fast-growing specie. Finally, this fact is noteworthy that in outdoor conditions, temperature and light have important role in growth of $C$. vulgaris in present study. (JASEM http://dx.doi.org/10.4314/iasem.v20i1.16
\end{abstract}

KEY WORDS: Chlorella vulgaris, Biomass, Photobioreactor, Growth.

\section{Introduction}

Nowadays with increasing the population, the importance of microalgae to supply food and energy is universally recognized more than ever before. However issues concerning sustainable and practical mechanism for culturing microalgae can be found almost in all over the world. Algae divided two photosynthetic organisms such as microalgae and macroalgae and they are often called primary producers because they are the important source of both cellular carbon and chemical energy for other organisms (Sirakov et al., 2015). Microalgae is one of the main producers of organic matter in aquatic ecosystems that inhabit the surface sunlight layer of fresh, brackish and salt bodies of water (Collier at al., 1978). Ecological requirements such as light, temperature or salinity are effective on the presence and growth intensity of the individual species and phytoplankton groups (Collier et al., 1978; Orus et al., 1991). Microalgae biomass consists of about $50 \%$ of carbon on a dry weight basis and also carbon dioxide is used for producing carbon in cells (Sanchez Miron et al., 2003). In the production of biomass, the importance of photosynthetic microalgae is more than plants that use light energy and carbon dioxide (Benemann, 1997; Miao and Wu, 2006). Microalgae are also crucially dependent on minerals such as macronutrients and micronutrients. They may be used to different applications, such as purification of wastewater under either autotrophic or mixotrophic conditions (Olaizola, 2003; Munoz and Guieysse, 2006), diesel replacements (i.e., coal, oil, and gas) (Illman et al., 2000), pharmaceutical products, food for aquaculture and are necessary in aquatic food webs (Spolaore et al., 2006). Changes in growth conditions (temperature and light intensity) or nutrient media characteristics (concentration of nitrogen, phosphates, and iron) can impact on quantity and quality of cells lipids (Mikulski 1982; Liu et al. 2008).Chlorella vulgaris is a small green microalga. It size is $2-10 \mu \mathrm{m}$ in diameter and has a high content of about $51-58 \%$ protein, $12-17 \%$ carbohydrate and $14-22 \%$ lipid (calculated as \% of dry matter) also it growth depends on environmental factors (Spolaore et al., 2006).The study of Seyfabadi et al. (2010) showed a protein concentration in $C$. vulgaris with different conditions of light regimes can be reached of 33-46\%. Putt (2008) reported under certain environmental factors the lipid content of C. vulgaris can be up to $30 \%$. One of the important properties of $C$. vulgaris is that it can be grown both autotrophically (the cell collects the energy from the light through photosynthesis) and heterotrophically (the cell only requires a carbon source as energy) (Seyfabadi et al., 2010; Larsdotter, 2006). Molina et al. (2000) reported that the used of PBRs for producing large amount of microalgae 
biomass are successful. There are several other algae that could be of interest in a study like this. Different algae have different condition and required a certain environment factors for growth. Open ponds are one of the primary and effective methods in large-scale and PBR is the alternate method for the production of microalgae (Lebeau and Robert, 2003). It can be installed indoors, receiving artificial or be prepared outdoors, getting visible light (Matos et al., 2014). In present experiment evaluated the effect of the main environmental factors such as light, temperature and lux on optical density, biomass and growth of Chlorella vulgaris in outdoor conditions in bucket, tub and PBR in Qeshm Island in Iran.

\section{MATERIALS AND METHODS}

Pure algal cultures were isolated from natural plankton communities of laboratory of biotechnology company in Qeshm Island in Iran where our outdoor area was there. Annual temperature in Qeshm Island ranged from $13^{\circ} \mathrm{C}$ to $39^{\circ} \mathrm{C}$ and is rarely below $10^{\circ} \mathrm{C}$ or above $40^{\circ} \mathrm{C}$. The C. vulgaris cultures were cultivated in sterilized natural seawater enriched with $\mathrm{F} / 2-\mathrm{Si}$ medium which contains $\mathrm{NaNO}_{3} 75 \mathrm{mg}, \mathrm{NaH}_{2} \mathrm{PO}$. $2 \mathrm{H}_{2} \mathrm{O} 5.65 \mathrm{mg}, \mathrm{Na}_{2}$ EDTA $4.16 \mathrm{mg}, \mathrm{FeCl}_{3}, 6 \mathrm{H}_{2} \mathrm{O}$ $3.15 \mathrm{mg}, \mathrm{CuSO}_{4} 5 \mathrm{H}_{2} \mathrm{O} 0.01 \mathrm{mg}, \mathrm{ZnSO}_{4} 7 \mathrm{H}_{2} \mathrm{O} 0.022$ $\mathrm{mg}, \mathrm{CoCl}_{2} 6 \mathrm{H}_{2} \mathrm{O} 0.01 \mathrm{mg}, \mathrm{MnCl}_{2} 4 \mathrm{H}_{2} \mathrm{O} 0.18 \mathrm{mg}$, $\mathrm{Na}_{2} \mathrm{MoO}_{4} \cdot 2 \mathrm{H}_{2} \mathrm{O} 0.006 \mathrm{mg}$, Vitamin $\mathrm{B} 120.0005 \mathrm{mg}$, Vitamin B1 $0.1 \mathrm{mg}$ and Biotin $0.0005 \mathrm{mg}$ per liter as described by Guillard (1962). C. vulgaris culture grew at first in indoor in lab after that transferred in outdoor condition in large volume in bucket, tub and PBR (cylindrical PBR, with vertical arrangement of the cylinder) Fig.1. The OD and $\mathrm{pH}$ should be noted every morning and evening. Daily routine work was culture checkups in terms of OD, biomass gains, atmosphere lux, culture lux, atmosphere temperature and culture temperature. Culture $\mathrm{pH}$ should be adjusted with $\mathrm{CO}_{2}$ gas whenever it is required. It should be always maintained at 7.0 and should not go beyond 7.5. In emergency condition, $\mathrm{pH}$ can be adjusted with 5\%$10 \%$ phosphoric acid. This maintenance is applicable for all the outdoor and large scale growth of the $C$. vulgaris cultures. Mixing is necessary to prevent sedimentation of the algae, to ensure that all cells of the population are equally exposed to the light and nutrients, to avoid thermal stratification (e.g. in outdoor cultures) and to improve gas exchange between the culture medium and the air. For high dense cultures, the $\mathrm{CO}_{2}$ derived from the air (containing $0.03 \% \mathrm{CO}_{2}$ ) bubbled through the culture is limiting the algal growth and pure carbon dioxide may be supplemented to the air supply (e.g. at a rate of $1 \%$ of the volume of air). $\mathrm{CO}_{2}$ addition furthermore buffers the water against $\mathrm{pH}$ changes as a result of the $\mathrm{CO}_{2} / \mathrm{HCO}_{3}{ }^{-}$balance. Depending on the scale of the culture system, mixing is achieved by daily stirring by hand (tubes, Buckets) and aerating (PBRs). In this study, growth experiments were done at different temperatures and lights in two times 8:00 AM and 15:00 PM in four months December, November, March and April in 2011. Algal daily growth changes measured in optical density at $500 \mathrm{~nm}$ with a spectrophotometer (UV757CRT) (Guillard, 1962). Cell numbers (cells $\mathrm{mL}^{-1}$ ) were counted under a microscope with a haemacytometer. Biomass concentration(dry weight per liter)was separated from the medium by centrifugation at $5000 \mathrm{rpm}$ for $15 \mathrm{~min}$, using a centrifuge model 42426 (ALC, Milan, Italy) then dried at $105^{\circ} \mathrm{C}$ for $48 \mathrm{~h}$, pulverized in a mortar and stored at $20^{\circ} \mathrm{C}$ for later analysis.

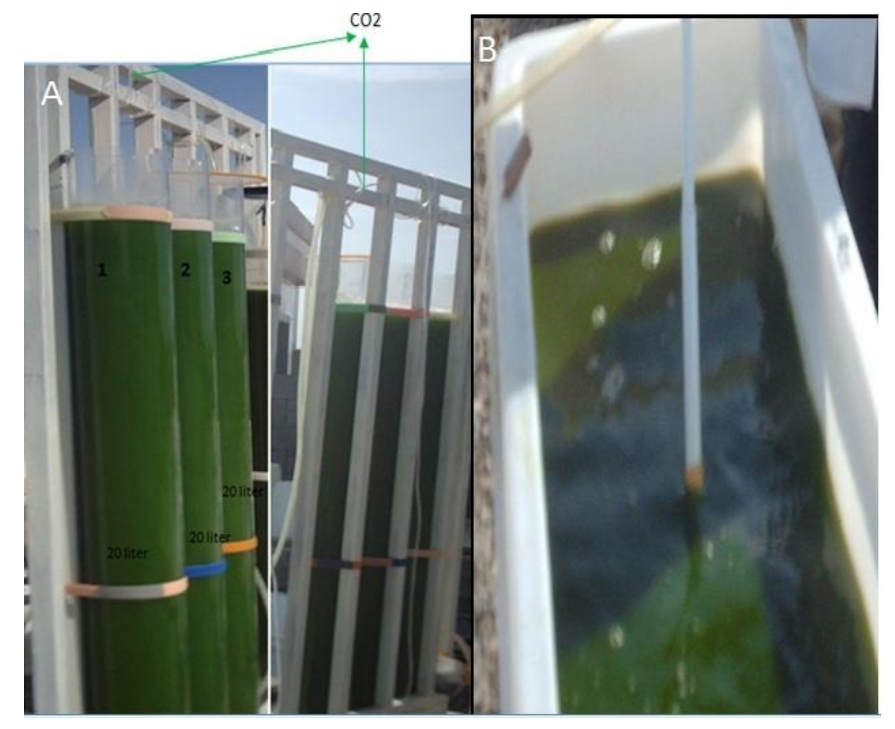

Fig.1. Growth of algae in photobioreactor (A) in tub (B) 
The growth of microalgae is characterized by the following five phases (Fig. 2.). Induction phase

During induction phase, a little increase observed in microalgae cell density and in this stage cultures have short $\log$ phases that can decrease the time needed for up scaling (Carlsson et al., 2007). Exponential phase During the second phase, the cell density increases as a function of time $\mathrm{t}$ according to a logarithmic function: $C_{t}=C_{0}$. $e^{\mathrm{mt}}$. With $C_{t}$ and $C_{0}$ being the cell concentrations at time $\mathrm{t}$ and 0 , respectively, and $\mathrm{m}=$ specific growth rate. The specific growth rate is mainly dependent on algal species, light intensity and temperature (Carlsson et al., 2007).

Phase of declining growth rate: In this stage many factors such as; nutrients, light, $\mathrm{pH}$, carbon dioxide or other physical and chemical factors limited the

microalgae growth and the cell division to be down slow (Carlsson et al., 2007).

Stationary phase: In the stationary phase, the cell density of microalgae is stable because the limiting factors and the growth rate are in balanced (Carlsson et al., 2007). 2.1.5. Death phase

In the final stage of microalgae, cell density decreases rapidly. That reason is the reduction of nutrient, oxygen dissolve, contamination and disorder of $\mathrm{pH}$. The key to the success of microalgae production in large scale is cultured it in the exponential phase of growth and before it reach to declining growth rate phase, all of culture to be subculture (Carlsson et al., 2007).

4

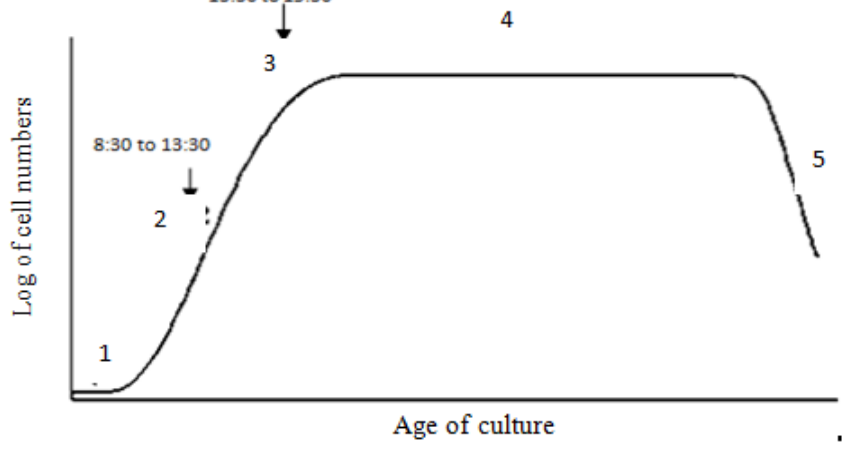

Fig.2.Growth diagram for Chlorella vulgaris, 1: induction phase 2: exponential phase 3 : phase of declining relative growth 4 : stationary phase 5 : death phase.

\section{RESULTS AND DISCUSSION}

PBR report: December and November: Amounts of temperature and light (lux) in two times 8:00 AM and 15:00 PM in two months December and November have been showed in (Table.1). Temperature and light in November was higher than in December also in 15:00 PM was higher than 8:30 AM. As a result from this experiment, optimum temperature in November was $28^{\circ} \mathrm{C}$ and in December was $25^{\circ} \mathrm{C}$. Fig $(3,4)$ presents the relationship between biomass and OD in November and December which indicated that the highest biomass yields were $(3.0 \mathrm{mg} / \mathrm{l}$ in December) and $(2.01 \mathrm{mg} / \mathrm{l}$ in November) cultured in $20-\mathrm{L}$ in outdoor PBR. The biomass productivity of $C$. zofingiensis by Feng et al. (2011) (58.4 $\mathrm{mg} \mathrm{L}^{-1} \mathrm{day}^{-1}$ ) in outdoor photobioreactor also biomass productivity of $C$. vulgaris (40 mg L_1 day_1) and C. emersonii (41 mg L_1 day_1) cultured in 230-L pumped tubular photobioreactor indoors reported by Scragg et al. (2002), indicating the advantage of outdoor culture (Feng et al., 2011; Scragg et al., 2002). The results of current study indicate that temperature affected the growth rate and biomass productivity (Table.1). Standard division and average condition factors in different times in December showed that the highest deviation was in atmosphere lux in time 8:30 $( \pm 117.7)$ and lowest deviation was in atmosphere temperature in time 15:00 ( \pm 1.0499$)$ (Table 2). 


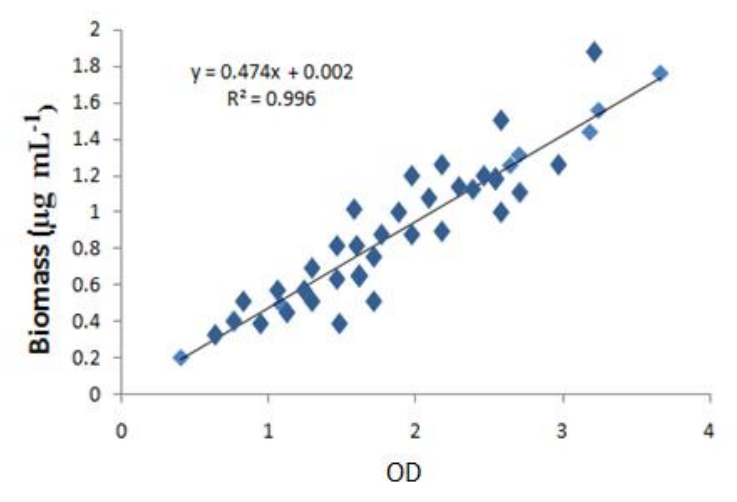

Fig.3. Relationship between Biomass and OD in photobioreactor in November (2011)

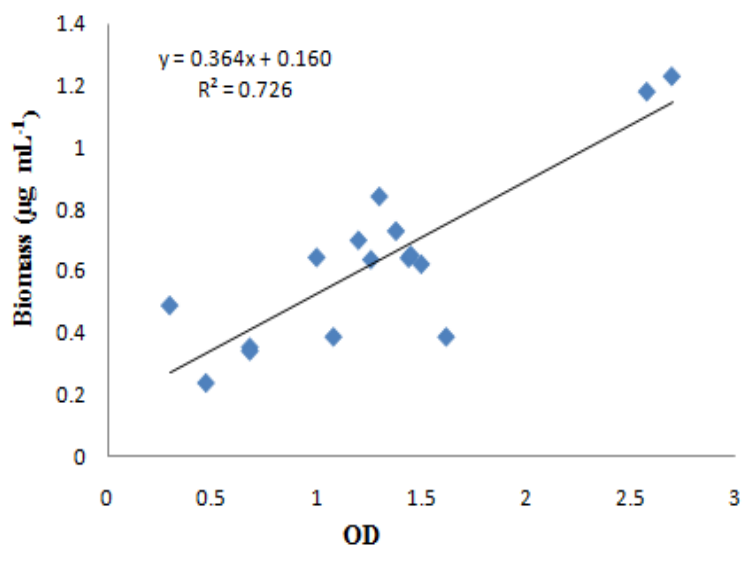

Fig.4. Relationship between OD and Biomass in photobioreactor in December (2011)

Table 1 Average of main parameters of $C$. vulgalris

(Maximum Minimum

\begin{tabular}{ccccc}
\hline Month & Time & A Temp $^{(\circ \mathrm{C})}$ & C Temp $^{(\mathrm{C})}$ & A lux \\
\hline November & 8:30AM & 25.5 & 32 & 412 \\
November & 8:30AM & 20.5 & 26 & 225 \\
November & 15:00PM & 28 & 42 & 253 \\
November & 15:00PM & 25 & 36 & 184 \\
December & 8:30AM & 24 & 27.5 & $\mathbf{5 5 0}$ \\
December & 8:30AM & 15.5 & 17.5 & 130 \\
December & 15:00PM & 25 & 40.5 & $\mathbf{2 7 2}$ \\
December & 15:00PM & 22 & 33.5 & 92 \\
\hline
\end{tabular}

Table 2: Standard Deviation and Average condition factors in different time in December (2011)

\begin{tabular}{lllll}
\hline $\begin{array}{l}\text { Atmosphere } \\
\text { temperature in time } \\
\mathbf{8 : 3 0}\end{array}$ & $\begin{array}{l}\text { Culture temperature } \\
\text { in time 8:30 }\end{array}$ & $\begin{array}{l}\text { Atmosphere temperature } \\
\text { in time 15:00 }\end{array}$ & $\begin{array}{l}\text { Culture temperature } \\
\text { in time 15:00 }\end{array}$ & $\begin{array}{l}\text { Atmosphere Lux } \\
\text { in time 8:30 }\end{array}$ \\
\hline $18.97 \pm 4.744$ & $22.625 \pm 4.706$ & $24.066 \pm 1.0499$ & $36.946 \pm 2.693$ & $247.26 \pm 117.7$ \\
\hline
\end{tabular}

Fig.5 shows the relationship between lux and average OD in time 11:30 in December. The OD indicated that the best growth of $C$. vulgaris was obtained in lux 650 and also the optical density increased with addition amount of lux. The relationship between lux and atmosphere temperature in November has been shown in (Fig.6). Results indicated that the lux in time 8:30 was higher than in time 13:30 but the temperature in time 13:30 was higher than in time 8:30. The effect of the unfavorable conditions on biological processes is generally dependent on time. Over a range of moderate temperatures and at low to medium light intensities (relative to the normal range of the plant species) the rate of photosynthesis increases as the intensity increases and is relatively independent of temperature. High temperature changes prevented the growth of algae and caused to lower biomass
(Coutteau, 1996). Illman et al. (2000) and Carlsson et al. (2007) reported that optimum temperature for growth of Chlorella was at $30^{\circ} \mathrm{C}-35^{\circ} \mathrm{C}$.

Bucket report: March and April: The intermediate culture was maintained in buckets as indoor and outdoor cultures. Indoor culture was placed inside the culture chamber under controlled light intensity and temperature. Outdoor culture was placed when light intensity was $\mathrm{min} / \max (25 / 71.6)$ Klux and temperature was $\mathrm{min} / \mathrm{max}(25 / 33)$. The $\mathrm{pH}$ was adjusted to 7.0 with 5-10\% phosphoric acid for indoor and with $\mathrm{CO}_{2}$ gas for outdoor cultures. Initial and final OD for indoor cultures was 0.25 and $0.51 \mu \mathrm{g} / \mathrm{ml}^{-1}$, respectively but for outdoor cultures, they were 0.32 and $0.62 \mu \mathrm{g} / \mathrm{ml}^{-}$ ${ }^{1}$ respectively(Fig.7). 


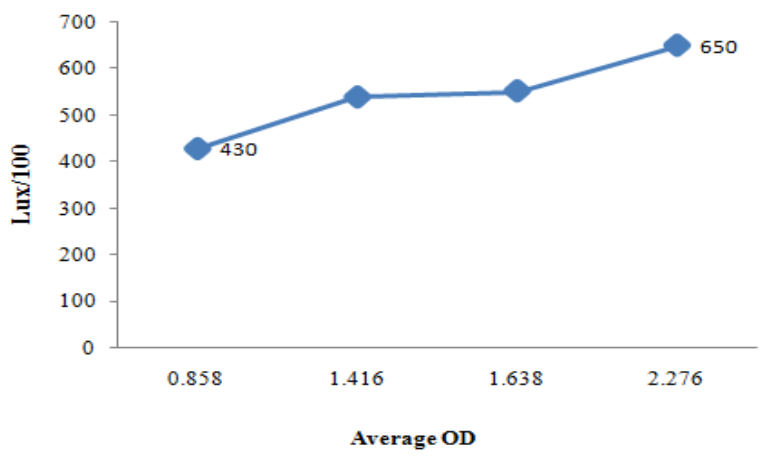

Fig.5. Relationship between Lux and Average OD in time 11:30 in December (2011)

Tub report: March and April During the months of March and April, the culture was good and without any contamination. $C$. vulgaris cells were small in size. $\mathrm{PH}$ of the culture was adjusted with $\mathrm{CO}_{2}$ gas and maintained in 6.8-7.0. In the case of high-density algal culture, the addition of carbon dioxide allows to correct for increased $\mathrm{pH}$, which may reach limiting values of $\mathrm{pH}$ up to 9 during algal growth. Initial average OD of the culture was 0.289 , biomass $0.2718 \mathrm{~g} / \mathrm{l}$. Final average OD of the culture was 1.68 , biomass $0.9877 \mathrm{~g} / \mathrm{l}$. Min/Max Culture temperature was $18{ }^{\circ} \mathrm{C}-30{ }^{\circ} \mathrm{C}$. Min/max-Light intensity (Klux) was 9.7/89 (Fig.8). The results of Feng et al (2011) on the cultivation of $C$. zofingiensis in the autumn compared the spring showed that the cells in the spring reached higher 1 max (day_1) and biomass productivity and these differences could be under the influence by the differences in temperature and light intensity during the two seasons (Carlsson et al., 2007).

Temperatures lower than $16^{\circ} \mathrm{C}$ will slow down growth, whereas those higher than $35^{\circ} \mathrm{C}$ are lethal for a number of species (Barsanti and Gualtieri, 2014). As with all plants, microalgae photosynthesize capable converted inorganic carbon into organic matter (Barsanti and Gualtieri, 2014). Light is the source of energy and light intensity plays an important role that requirement to light substantially dependent on the culture depth and the density of the algal culture (Barsanti and Gualtieri, 2014). In this study at time 8:30 to $13: 30 C$. vulgaris were in exponential phase and were in phase of defining relative growth at time 13:30 to 15:30 (Fig.2). C. vulgaris showed different growing

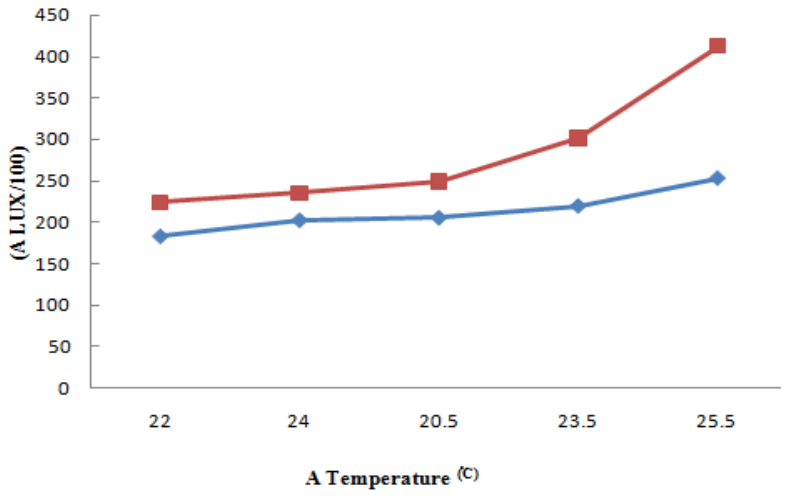

Fig.6. Relationship between Lux and Atmosphere temperature in November (2011) (Time 8:30 Time 13:30 $\diamond$ )

behaviors at the various amounts of light and at the different temperatures. Significant increases in biomass productivities have been achieved in enclosed PBR with the use of a powerful light source and efficient light distribution (Miao and $\mathrm{Wu}, 2006$ ). Many factors that influenced the growth of $C$. vulgaris were clarity of the water, time of day, effective range of sunlight, shape, color or transparency of the container, wall thickness and size of the container. Clear transparent PBR can be effective in absorption of visible light (Lee and Palsson, 1994). The PBRs is more expensive compare than open ponds but more harvested biomass (Chisti, 2007). The production of microalgae biomass for biodiesel goal showed that the Raceway ponds cost less money than PBRs, but the productivity of biomass is also lower than PBRs (Sheehan et al., 1998). In present experiment the growth and biomass in PBRs was higher than of bucket and tub, however the atmosphere temperature in December to November was lower than April to March in Qeshm Island. PBRs have recently attracted a considerable attention for the production for special applications. For high-density cultures, the optimization of environmental factors including light delivery, $\mathrm{CO}_{2}$ and $\mathrm{O}_{2}$ in the PBRs have been explored (Lee and Palsson, 1994). PBR that can be installed in areas that do not require flat land thus for some of aquaculture goal in large scale it is a good choice. For production of high-value microalgae products, light intensity and photoperiod are most important factors for growth rate and biomass composition (Khoeyi et al., 2012). 


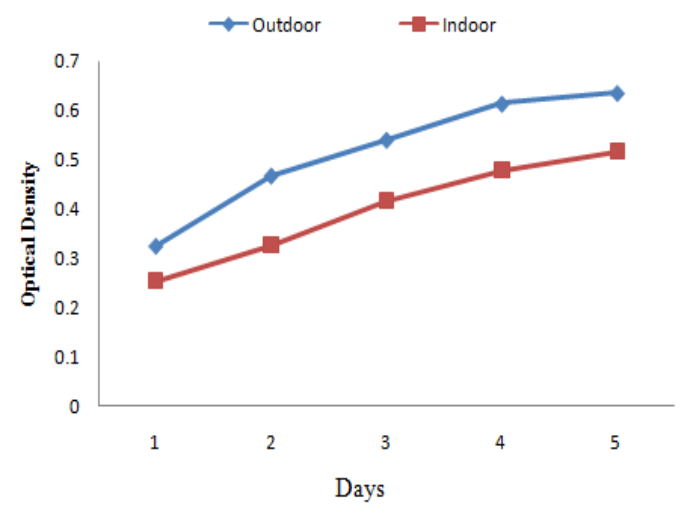

Fig.7. Optical density in different days in indoor and outdoor conditions in March and April (2011)

Conclusion: The results of current study indicated that the algae biomass production of C. vulgaris in PBRs was more than of bucket and tub. Also growth algae in outdoor PBR are relatively inexpensive, but are only suitable for a few, fast-growing. Outdoor production in PBRs has often unpredictable culture crashes caused by changes in weather, sunlight or rainfall. Finally, this fact is noteworthy that in outdoor conditions, temperatures and light have important role in growth of $C$. vulgaris in this study. The using of ways with lowest cost and lowest needed mineral, elected a suitable place for outdoor photobioreactors, tub and pond aspect of enough light, temperature and lowest contamination are a necessary for better growth $C$. vulgaris and highest biomass. It recommended that in an industrial scale the used of balcony water of harvesting $C$. vulgaris can be a good idea for irrigation of flowers and trees in the factory.

Acknowledgements: We are grateful to Mr. Khalaj babayi and administer of Biotechnology Institute of Qeshm Islnad for providing the equipments and materials of laboratory.

\section{REFERENCES}

Barsanti, L; Gualtieri, P (2014). Algae: Anatomy, Biochemistry, and Biotechnology. Second edn. CRC Press, pp 361. DOI: 10.1201/b16544-1.

Benemann, JR (1997). CO2 mitigation with microalgae systems. Energy Convers Manage 38:475-479.

Carlsson AS; Beilen, JB; Moller, R; Clayton, D (2007). Micro-algae and macro-algae: utility for

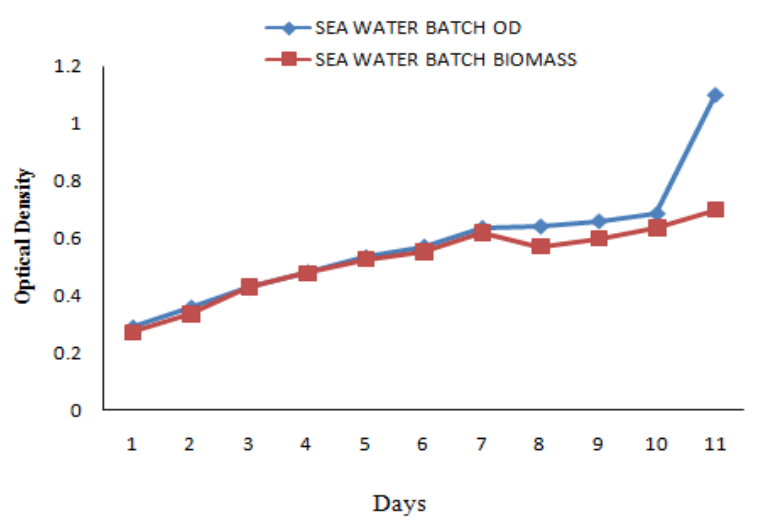

Fig.8. Optical density and Biomass in different days in March and April (2011)

industrials applications. In: (ed) Dianna Bowles, pp 9-33.

Chisti, Y (2007). Biodiesel from microalgae. Biotechnology Advances 25:294-306.

Collier, BD; Cox, GW; Johnson, AW; Miller, PC (1978). Dynamic ecology. PWRiL, Warszawa, (in Polish).

Coutteau, P (1996). Micro-algae. In: Lavens, P; Sorgeloos, P (ed). Manual on the production and use of live food for aquaculture. FAO Fisheries Technical, FAO,Rome, pp 7-48.

Feng, P; Deng, Z; Hu, Z; Fan, L (2011). Lipid accumulation and growth of Chlorella zofingiensis in flat plate photobioreactors outdoors. Bioresource Technology 102:1057710584 .

Guillard, RRL (1962). Salt and osmotic balance. In: Lewin, RA (ed) Physiology and biochemistry of algae. Academic Press, New York- London, pp 529-540.

Illman, AM; Scragg, AH; Shales, SW (2000). Increase in Chlorella strains calorific values when grown in low nitrogen medium. Enzyme Microb Technol 27: 631- 635.

Khoeyi, ZA; Seyfabadi, J; Ramezanpour, Z (2012). Effect of light intensity and photoperiod on biomass and fatty acid composition of the microalgae. Chlorella vulgaris. Aquac Int 20:4149. 
Larsdotter, K (2006). Wastewater treatment with microalgae - a literature review. Vatten 62:31-38.

Lebeau, T; obert, JM (2003). Diatom cultivation and biotechnologically relevant products. Part I: Cultivation at various scales. Microbiol Biotechnol 60: 612-23.

Lee, CG; Palsson, BO (1994). High-density algal photo bioreactors using light-emitting diodes. Biotechnol Bioeng 44:1161-1167.

Liu, ZY; Wang, GC; Zhou, BC (2008). Effect of iron on growth and lipid accumulation in Chlorella vulgaris. Bioresour Technol 99:4717-4722.

Matos, AP; Torres, RCO; Morioka, RLI; Moecke, EHS; Franca, KB; Anna, ESS (2014). Growing Chlorella vulgaris in Photobioreactor by Continuous Process Using Concentrated Desalination: Effect of Dilution Rate on Biochemical Composition. International Journal of Chemical Engineering 2014: 1-6. http://dx.doi.org/10.1155/2014/310285

Miao, X; Wu, Q (2006). Biodiesel production from heterotrophic micro algal oil. Bioresour Technol 97:841-846.

Mikulski, JS (1982) Biology of inland waters. PWN, Warszawa (in Polish).

Molina, GE; Acien, FG; Garcia, CF; Camacho, RF; Chisti, Y (2000). Scale-up of tubular Photobioreactors. Journal of Applied Phycology 12: 355-68.

Munoz, R; Guieysse, B (2006). Algal-bacterial processes for the treatment of hazardous contaminants: a review.Water Res 40:2799-2815.

Olaizola, M (2003). Commercial development of microalgal biotechnology: from the test tube to the marketplace. Biomol Eng. 20: 459-466.

Orus, MI; Marco, E; Martinez, F (1991). Suitability of Chlorella vulgaris UAM 101 for heterotrophic biomass production. Bioresour Technol 38:179184.
Putt, R (2007). Algae as a biodiesel feedstock: A feasibility assessment. Auburn, AL: Center for Microfibrous Materials Manufacturing (CM3). Department of Chemical Engineering, Auburn University.

Sanchez Miron, A; Ceron Garcia, M.C; Contreras Gomez, A; Garcia Camacho, F; Molina Grima, E; Chisti, Y (2003). Shear stress tolerance and biochemical characterization of Phaeodactylum tricornutumin quasi steady-state continuous culture in outdoor photobioreactors. Biochem Eng J 16:287-297.

Scragg, AH; Illman, AM; Carden, A; Shales, SW (2002). Growth of microalgae with increased caloric values in a tubular bioreactor. Biomass and Bioenergy 23:67-73.

Seyfabadi, J; Ramezanpour, Z; Khoeyi, A (2011). Protein, fatty acid and pigment content of Chlorella vulgaris under different light regimes. Journal of applied phycology 23:721-726.

Sheehan, J; Dunahay, T; Benemann, J; Roessler, P (1998). A look back at the U.S. Department of Energy's aquatic species program: Biodiesel from algae. National Renewable Energy Laboratory NREL. [Online] National Renewable Energy Laboratory NREL 7 1998.[Cited: 2611 2008.] http://www.nrel.gov/docs/legosti/fy98/24190.pdf. NREL/TP-580-24190.

Sirakov, I; Velichkova, K; Stoyanova, S; Staykov, Y (2015). The importance of microalgae for aquaculture industry. Review. International Journal of Fisheries and Aquatic Studies 2: 81-84.

Spolaore, P; Joannis-Cassan, C; Duran, E; Isambert, A (2006). Commercial applications of microalgae. J Biosci Bioeng 101:87-96. 